\title{
Editorial: JMG Symposium on "Evaluation, performance and governance in the digital age"
}

\author{
Lino Cinquini ${ }^{1}$
}

Published online: 25 November 2019

(c) Springer Science+Business Media, LLC, part of Springer Nature 2019

This last issue of 2019 opens with the articles of the two invited speakers of the JMG Symposium on "Evaluation, performance and governance in the digital age" organized within the 39th National Conference of the Accademia Italiana di Economia Aziendale (AIDEA) held in Turin on 12-13 September 2019.

The general theme of the Conference has been focused on the era of digitalization and the digital economy, to reflect on the direction that business sciences should now take in the light of the profound and disruptive transformations that are rapidly changing contexts and models of management and business competition.

In particular, the angle explored in the Symposium has concerned a reflection on how the comprehensive digitalization of the language is changing human practices, including the practice of governance, evaluation and performance management of organizations. In this respect, it is important for research to explore issues concerning the risk of de-contextualization from specific organizational activities and conditions in the production and use of information for decision-making and performance management.

Thus, new issues may arise from the pervasive and uncritical use of digital approach in organizations, especially the risk of de-contextualization of data from the specific factual situation and alternative possibilities for actions, which can have important dysfunctional consequences for the individual and organizational performance. When the specific context is neglected in organizational decision-making and performance management, a culture might emerge where "truth" is centralized and the value of truth and trustworthy performance measurement collapse.

In this perspective, Artificial Intelligence (AI) and Big Data might indicate how decision-making would be uncontextualized, and people and local setting may become irrelevant. Thus, the questions about the consequences for human actors and their roles in pervasive digitalization and how can we develop fair and valid performance management instruments for making managers and employees accountable are important.

Lino Cinquini

1.cinquini@santannapisa.it

1 Institute of Management, Scuola Superiore Sant'Anna, Pisa, Italy 
The two papers presented in the Symposium by the invited speakers well address some of the relevant aspects of these issues.

The article by Thomas Bolander, "What do we loose when machines take the decisions?", points out the weaknesses that AI techniques still have, and that one should be aware of when considering to implement AI to automate human decisions. His clear argumentations highlight the risk that currently people and organisations incur to fully automate certain crucial aspects of decision making without waiting for these limitations and weaknesses to be reduced-or, even worse, not even being aware of those weaknesses, and of what is lost in the automatisation process.

The contribution "Moving towards digital governance of university scholars: instigating a post-truth university culture" by Lennart Nørreklit, Lisa Jack and Hanne Nørreklit, focuses on the impact of digitalization in the governance of professional organizations like universities. In particular, it addresses how the language embedded in the production and use of data for governance models based on information technology may facilitate a governance culture that limits or excludes the scholarly insights of the same university professionals.

Although not exhausting the theme of the Symposium, these contributions feed a debate on aspects of the ongoing process of pervasive digitalization which deserve consideration in contemporary research in management and governance.

Lino Cinquini is Professor of Business Administration and Management Accounting at the Institute of Management, Sant'Anna School of Advanced Studies of Pisa (Italy), where he is member of the Teaching Board of the Ph.D. in Management and Direct or of M.Sc. in Innovation Management. His research areas are Management Accounting, Cost management, Strategic Management Accounting and Performance measurement in private and public sector. He has been co-editor of Journal of Management and Governance (2007-2015), Editor-in-Chief since 2016, and currently a member of the Editorial Board of Journal of Accounting and Organizational Change and Qualitative Research in Accounting and Management. He is Research Board Member of the Chartered Institute of Management Accountants (CIMA: UK). Personal Homepage: https://www.santannapisa.it/it/lino-cinquini. 